\title{
BARTOLOMÉ HERRERA, EL SACERDOTE EDUCADOR DE MINORÍAS SELECTAS DEL PERÚ NACIENTE
}

\author{
José Antonio Benito Rodríguez* \\ Universidad Católica Sedes Sapientiae \\ jbenito@ucss.edu.pe
}

Resumen: En este ensayo se presentará la dimensión sacerdotal como elemento fundamental en la misión del educador Bartolomé Herrera. Nos centraremos en este rasgo capital de su persona, ya que consideramos que desde esta brotó su actividad educadora, su docencia universitaria y también sus compromisos políticos y pastorales, que sirvieron para forjar personalidades decisivas en la formación del nuevo estado peruano. Para ello hemos acudido a las fuentes más directas como los archivos arzobispales de Lima y de Arequipa, así como a sus biógrafos y críticos, sin dejar de lado

* José Antonio Benito Rodríguez es doctor en Historia de América por la Universidad de Valladolid (España) y diplomado en Educación por la Universidad de Salamanca (España). Es Miembro Ordinario de la Asociación Española de Americanistas, de la sección de Historia del Instituto Riva-Agüero de la PUCP y de la Academia Peruana de Historia de la Iglesia. Como conferencista ha sido reconocido tanto en el Perú como en el extranjero. Ha publicado numerosas investigaciones en volúmenes y revistas nacionales e internacionales. Asimismo, es director del Centro de Estudios del Patrimonio Cultural (CEPAC) de la UCSS y Director del Instituto de Estudios Toribianos. Conduce el programa de televisión El Puente, transmitido por el canal católico PAX TV. Es docente principal de la Universidad Católica Sedes Sapientiae (UCSS), profesor asociado de la Facultad de Teología Pontificia y Civil de Lima y profesor de la Facultad de Teología Redemptoris Mater (Callao, Lima) 
sus más recientes estudiosos con motivo del bicentenario de su nacimiento acaecido en el 2008.

Palabras clave: Bartolomé Herrera, sacerdote, Convictorio San Carlos, educador

\title{
BARTOLOMÉ HERRERA, THE EDUCATIONALIST PRIEST OF SELECTED SMALL GROUPS IN THE RECENT RISING PERU
}

\begin{abstract}
In this essay we will deal with the priestly dimension as main element in Bartolomé Herrera's mission. We will focus on this principal personality feature from which his pastoral mission, his university activity as well as his political and pastoral commitment raised. These characteristics were very crucial in the formation of other decisive celebrities who could contribute in the formation of the new Peruvian state. For this article, we have researched primary sources such as archiepiscopal archives from Lima and Arequipa. We have also talked to his biographers and critics, including the latest researchers who have done a study commemorating the bicentenary of his birth in 2008.

Kerwords: Bartolomé Herrera, priest, Convictorio San Carlos, educator.
\end{abstract}




\section{LA ACTUALIDAD DEL SACERDOTE EDUCADOR 200 AÑOS DESPUÉS}

El 24 de agosto del 2008, fiesta de San Bartolomé, se cumplió el bicentenario del nacimiento de Bartolomé Herrera. Fue limeño y gozó, tan solo, cinco años con sus padres Manuel José Herrera y Paula Vélez ${ }^{1}$, pues ellos murieron en 1813. El niño —al igual que su hermano- quedó bajo la custodia de su tío materno Luis Vélez, cura de Santa Ana. Fue alumno interno del Convictorio de San Carlos desde febrero de 1823. Con solo quince años, estudia filosofía, matemáticas y teología, graduándose como maestro en Artes. Inclinado a la Jurisprudencia, acogió la orientación del rector de San Carlos, José Manuel Pedemonte, de estudiar primero Teología. Todavía era cursante de esta disciplina -con solo dieciocho años de edad- cuando le dieron una cátedra de Filosofía, en julio de 1827. Desde esa fecha hasta el año 1831, continuó enseñando Filosofía y Matemáticas. En 1828 se doctoró en Teología en San Marcos.

1 «Certificado. Certifico yo el Infrascrito Teniente de los Curas Rectores de Señora Santa Ana que en un libro de papel común forrado en pergamino en que se sientan las partidas de Bautismo de españoles que empezaron a correr el año de 1803 y finalizó en 1815 (folio 168) con el tenor siguiente: Partida: En esta Iglesia, a 20 de octubre de 1808, Don Antonio José Oyagüe, capellán militar, exorcicé, pulse óleo y crisma a Bartolomé de dos meses, cuatro días a quien por necesidad yo mismo bauticé, es hijo legítimo de don Manuel de Herrera y de Rodríguez. Fue su padrino don Casaverde y lo firmé Dr. Antonio José Ollagüe. Santiago Astigarraga. Testigos: Agustín, Negrón y Félix Casaverde y lo firmé, Dr. Fdo. Pablo Chagaray, 16 de mayo de 1825». 
Será por este tiempo cuando una crisis emocional estuvo a punto de cambiar su destino. Efectivamente, se enamora de la joven N. Rueda con quien decide contraer matrimonio. Lo sabemos por una carta del Rector del Convictorio, José Manuel Pedemonte, con quien se entrevistó el propio Herrera para informarle de su decisión. El Rector, quien tenía fundadas esperanzas en el alumno que consideraba como un hijo, le disuade y anima a conversar con el sacerdote Francisco de Paulo Eraso, canónigo teologal del cabildo de Lima:

Colegio y octubre 30 de 1828. Mi apreciadísimo y estimado amigo: cabalmente he sabido que ayer fueron a pedir a Ud. Licencia para que el Sr. D. Bartolomé Herrera, maestro de este colegio, se case con doña N. Rueda. A este joven he hecho hoy ver el desatino que iba a hacer y me ha prometido suspenderlo y me dijo también que Ud. había dicho me vería para hablarme sobre el particular: si esto segundo es cierto, suplico a Ud. se mantenga en que es preciso verme. El joven, como digo, está determinado a suspenderlo y hablando yo con Ud. Se convencerá del desatino que iba a hacer. Páselo Ud. bien y mande a su afmo. servidor, amigo y capellán q.s.m.b. Manuel José Pedemonte (Colección Vargas, Mss. 33).

En 1831 — con tan solo veintitrés años- ejerce como vicerrector del Colegio de Minería y profesor de Matemáticas y Ciencias en Huánuco. Es ordenado en este mismo año y, con dispensa de la Santa Sede, continúa los estudios de Derecho. En 1833 regresa a Lima y funge como regente de Matemáticas, Teología y Artes en San Carlos, hasta que en 1834 alcanza el doctorado en Derecho. 
Como reconoce en su Testamento, desde 1834 fue cura de Cajacay (Cajatambo) y alrededores como Chancayan, Ruquia y otros tres pueblos. En 1837 actúa como Secretario de la visita pastoral del Arzobispo Jorge Benavente y es nombrado cura de Lurín y Pachacamac. Aquí se relaciona con el militar José Rufino Echenique y es convocado a Lima por su arzobispo Pasquel. En este tiempo, fue canónigo y chantre de la Iglesia catedral de Lima. Posteriormente, es nombrado Rector del Colegio de San Carlos por espacio de diez años- y procura «corresponder con todas mis fuerzas al beneficio de la educación». Realiza esta labor, simultáneamente, con el compromiso en la vida pública. Ejerce como diputado por Lima en 1849 y se convierte en el presidente de la cámara. Con el presidente Echenique será Ministro de Justicia y de Culto, así como Embajador del Perú ante la Santa Sede. En 1852 viaja a Roma para gestionar un concordato. En 1854 funda el semanario El Católico. En 1857 vuelve a ser diputado. En 1859 fue nombrado obispo de Arequipa, donde ejerce un fecundo e intenso apostolado en los pocos años de vida, ya que fallece el 10 de agosto de 1864 , con tan solo cincuenta y seis años. ${ }^{2}$

El claretiano P. Antonio San Cristóbal, en ese momento, Decano de la Facultad de Educación de la PUCP, pronunció la oración en la solemne misa de réquiem en la Catedral de Lima, destacando como clave de su vida su faceta de maestro de la democracia peruana como "hombre de su tiempo»:

Bartolomé Herrera es un hombre sumergido íntegramente en el Perú que nace a la existencia histórica. Toda la vida de Bartolomé Herrera ha sido un ardiente y sincero servicio a la Iglesia del Perú [...]. Es el primer peruano en quien la política se eleva a

2 Archivo Mercedario Arequipa Goyeneche. DOC 1794-1868, Leg. 7 F.74 
ideas sistemáticas y aspira a ser la expresión de un pensamiento orgánico [...]. Con Bartolomé Herrera alcanza en el Perú su máxima expresión la presencia del sacerdote en la vida pública [...]. Pienso que Bartolomé Herrera es el hombre genial que concibe por primera vez en el Perú un nuevo orden social basado en ideas nuevas [...]. Vive su cristianismo en la plenitud del saber racional y acude presuroso a la filosofía más moderna de su tiempo porque comprende que su filosofía vuelve de prisa hacia el catolicismo y va abrazando de una en una sus verdades. Mi religión es la de mi Iglesia y mi filosofía la de mi tiempo [...] tomado de la fuente en que bebe hoy todo el mundo científico. (Gran Unidad Escolar Bartolomé Herrera 1964: 20-31, el resalte es nuestro)

\section{MAESTRO ACLAMADO POR VOCES DE DOS SIGLOS}

Sus últimas palabras en el Testamento le pintan de cuerpo entero:«Declaro que fui Rector del Colegio de San Carlos, cerca de diez años, en cuyo tiempo procuré corresponder con todas mis fuerzas al beneficio de la educación que recibí en beca de merced en aquel colegio (Convictorio de San Carlos)». ${ }^{3}$ Voces autorizadas de sus biógrafos y comentaristas, a lo largo de estas dos centurias, coinciden en destacar su faceta educativa, como se constata a continuación:

- Jorge Leguía: en su excelente introducción a las obras de Herrera, nos manifiesta:

3 AGN, Protocolo 467, ff.1051, Notario Manuel Alcázar 
Somos francamente anti-reaccionarios, por carácter y convicción; en muchas oportunidades hemos abrigado prejuicios contra la personalidad del ilustre reaccionario; sin embargo, cuanto más lo estudiamos, cuanto más lo comprendemos, cuanto en mejor aptitud nos hallamos para juzgarlo, no podemos menos que reconocer su altísimo valor y sentir, aunque sea oblicuamente, la irradiación de su esclarecida personalidad. (Herrera 1930: I-XXII)

- José Arnaldo Márquez: su alumno más obstinado y opuesto, no dejará de reconocer el hecho de que "pocos hombres podrán ser tan simpáticos, persuasivos y sagaces [...] y si fue excesivamente severo y aún injusto conmigo en varias ocasiones, lo hizo por corregir los instintos demasiado altivos de mi carácter, y por no ceder en su plan de formar».

- José Jiménez Borja: subrayará: «Bartolomé Herrera es al mismo tiempo la doctrina, la acción, el fruto, el hondo tajo sobre el destino nacional» (1949).

- José Antonio Barrenechea: afirmará que su doctrina era una protesta contra los pronunciamientos de cuartel. Su personalidad es, por la altura de sus logros, la calidad de sus frutos, realmente excepcional. Estamos ante un hombre luchador, peleador, combativo. Este rasgo de su carácter será enfatizado por su biógrafo Leguía: «Herrera era un combativo de nacimiento. Su táctica fue: atacar, siempre atacar [...]. Se consume, en fin, porque la pasividad en su temperamento belicoso lo aniquila más que el bacilo de Koch». Su programa «jamás dejará de ser invocado por toda conciencia en la cual el civismo se mantenga indemne». 
- José Carlos Mariátegui dirá de él: «Tuvimos en don Bartolomé Herrera una insigne figura eclesiástica de estadista» (1941: 2950). ${ }^{4}$

- Rubén Vargas Ugarte: le otorga las cualidades de líder indiscutible: «Él era un educador y maestro, por vocación, poseía todas las dotes que se exigen en el que ha de ser conductor de juventudes, talento, facilidad de palabra, inalterable bondad, conocimiento del corazón humano, simpatía personal, noble presencia y un dominio de las materias que enseñaba que lo hacían estimar y admirar por sus alumnos» (1984: 149).

-Nelson Herrera Retuerto: se centró en su personalidad de Educador: «Hoy día queremos tributar nuestro rendido homenaje a quien desde su tiempo (1840-60) supo con inteligencia nunca vista dictarnos una lección inolvidable: que la educación y la política no son dos realidades opuestas, encontradas o distintas, antes bien, son una misma realidad indivisible, inseparable» (1984: 57).

- José Pareja Paz Soldán: quien fue Director de la Academia Diplomática del Perú, enfatizó sus valores como Hombre de Estado: «He considerado oportuno destacar la modernidad de algunos planteamientos constitucionales y políticos del maestro carolino como el problema capital de que dentro de una sana jerarquía democrática de valores, es necesario fusionar las ideas de libertad e igualdad con la de disciplina y capacidad por lo que se puede considerar como el precursor de teorías políticas de toda actualidad y utilidad» (1984: 79).

4 Esta nota se encuentra en «Monseñor el favorito». El tiempo, Lima, 12 de junio de 1917. Para consulta véase Mariátegui 1994. 
- Jorge Castro Harrison: en la extensa semblanza de su vida y obra, remarcará que «desarrolló una política de progreso procurando reafirmar la soberanía y autodeterminación nacional para el logro de intensificar el comercio con Europa, dio impulso a la inversión de préstamos internacionales, celebró el tratado de Navegación Fluvial que en representación del Brasil redactara Duharte Daponte Riveyro y se estableció un arreglo de límites con dicho país [...]. Poseyó sobre todo una subyugante gallardía espiritual» (1984: 84137).

- Manuel G. Abastos: «Herrera, ejemplo de hombre de energía, fue patriota y honrado; su autorizada palabra de tribuno y su vibrante pluma prestaron grandes servicios al país. Su fecundo pensamiento perpetuado en obras notables, nos muestran al hombre de estudio, cuya principal tarea fue la de educar» (Moreno 1956: 265-270).

- Francisco García Calderón Rey «Dogmático en virtud de su profesión religiosa, conservador, preocupado por las tradiciones y empeñado en dar a la democracia una nueva doctrina, es por la austeridad de su vida y la fuerza de su espíritu una de las bellas figuras del Perú republicano» (Moreno 1956: 265-270).

- Ricardo Mariátegui Oliva: «A él, a este gran peruano, se le debe como celoso guardián de la integridad territorial la defensa de la soberanía nacional frente a las pretensiones de USA sobre las Islas de Lobos; la implantación en Lima en 1853 de esa gran obra caritativa que se llama Conferencia de San Vicente de Paúl; el establecimiento de las Religiosas del Sagrado Corazón [...] y también el establecimiento de los primeros misioneros franciscanos 
que vinieron con el P. Pedro Gual, radicándose en el Convento de los Descalzos» (Moreno 1956: 265-270).

- Raúl Porras Barrenechea: «Ninguna generación, seguramente, salió de San Carlos con convicciones más firmes y claras, y con ideas más definidas sobre las grandes cuestiones políticas del país y sobre los conflictos del Derecho de Gentes que la educada por Herrera. Ninguna se halló, por tanto, mejor preparada para la vida pública. A los pocos años de regresada del Convictorio aquella juventud, y llegada al periódico y a la cátedra, al escaño parlamentario o al sillón ministerial, se hacía clásica la lucidez y el acierto, la profunda cultura jurídica con que los discípulos de Herrera discutían cuestiones políticas de soberanía, de patronato o de competencia entre los poderes públicos o cuestiones internacionales sobre la extensión de la jurisdicción y de la territorialidad» (Moreno 1956: 265-270).

-Luis Alberto Sánchez: analiza el gesto de Herrera en la Oración Fúnebre por el Presidente Gamarra, cuando era párroco del pueblo de Lurín: «Era un momento difícil. Por mucho que el acto se realizara en una iglesia, había que considerar el sentimiento nacional herido; la indignación latente. Un orador que se atuviera estrictamente a su cometido formal resultaría pálido e inoportuno. Uno demasiado espontáneo, peligroso e impropio. Había que combinar la inspiración con el deber, lo religioso con lo profano. Precisaba mezclar el impulso católico universal con el ímpetu peruanista, local y patriótico» (Moreno 1956: 265-270).

-Agustín de Asís: en su tesis doctoral acerca de su pensamiento político lo calificará como el hombre «de razón más clara, talento 
más ordenado y percepción más rápida de que puede gloriarse el clero del Perú» (1954: 1).

-Fernando Iwasaki Cauti: «Herrera no fue un político antidemocrático y retrógrado; considerarlo así sería caer en sincretismos. Pensamos, más bien, que fue un demócrata mucho más realista y objetivo que los de su tiempo; que fue el único que diseñó un proyecto nacional a largo plazo y el que asumió con más objetividad los problemas económicos y sociales del Perú» (1984: 138).

- José de la Puente y Candamo: se refiere a la visión profética de Herrera acerca de un Perú ilusionado y esperanzador:

Viven en Herrera, como en los hombres que en su juventud encuentran a la República naciente, ese mensaje de ilusión en años mejores que pertenece también a la ideología de la emancipación [...]. El Perú debe cumplir su propio destino ¿Cuáles son los obstáculos que se presentan para la realización de ese destino? Que la ley no merezca la obediencia de todos, que el orden no sea el fruto de una viva justicia, que la inseguridad perturbe la quietud de la gente, que pierda optimismo en el porvenir de la República. Con estos signos vive Herrera el primer tiempo republicano en el cual asume alta función directiva. Como Rector de San Carlos, parlamentario y hombre de Estado, siempre lucha por la misma idea: obediencia a la ley, respeto a las instituciones y vive asimismo su ideal permanente de maestro: formar una clase directora no por el nombre ni por la fortuna, sino por la calidad intelectual, la delicadeza moral y la voluntad de servir. Y este es el Perú que estudia y contempla Herrera con 
una vocación de unidad y desasosiego que viene de la historia creadora, de la raíz mestiza del Perú. (1965: 80-83)

- Ricardo Cubas Ramacciotti: rescata su «visión teológica de la historia del Perú que reivindicó el papel de la fe en la formación de la cultura peruana» y la reconciliación de las tradiciones históricas del país; criticó los efectos de las ideologías de la Ilustración en el Perú, valorando su propuesta de «una élite intelectual católica que reformara la política y la iglesia peruana» (2001: 111).

- Jorge Putnam Velando: destaca su sereno diálogo con las diversas corrientes ideológicas desde su filosofía tomista que fructificó en el Proyecto Constitucional de 1860, basado en un gobierno presidencialista, asistido por un grupo de representantes sociales; supo mantenerse fiel al Magisterio eclesial a pesar del fuerte regalismo imperante (2001: 514-519).

\section{A PESAR DE BASADRE}

El patriarca de nuestra historia republicana, Jorge Basadre, en su escrito «En torno a los escritos y discursos de Bartolomé Herrera» (Herrera 1930: LXVILXXXI) le echa en cara el que «no se olvida nunca de que es sacerdote; y sacerdote de los fanáticos. Toda su concepción filosófica, política e histórica está inspirada en su proselitismo religioso». Al denostarlo, le ennoblece porque es imposible quitarle a Herrera su alma sacerdotal, como muy bien lo intuyó su maestro y rector del Convictorio Mariano José Pedemonte. Le critica también el paso al escolasticismo, desde su antigua mentalidad jansenista y ecléctica. Ironiza el insigne polígrafo sobre lo que a él le parece 
acomodaticio y endeble providencialismo en Herrera. ${ }^{5}$ Concluye en que «un hombre así tiene que ser forzosamente dogmático [...]. Seguramente, el escepticismo le parecía un absurdo moral e intelectual, una aberración [...]. Desconocía la tolerancia, la comprensión para el enemigo, el amor a todo lo viviente». De igual modo, al analizar la doctrina de Bartolomé Herrera sobre «la minoría directora» le echará en cara el desinterés de Herrera por la masa: «esa masa que Herrera desdeñaba porque creía que el patriotismo es caridad cuando es justicia». También le parece excesiva su crítica a la Revolución Francesa, la que según Herrera fue una «memorable catástrofe» y no «un hecho capital en la historia del mundo que trajo algunos principios básicos para la civilización", a juicio de J. Basadre. ${ }^{6}$ A pesar de ello, el historiador Basadre termina por destacar dos puntos en los que está de acuerdo con Herrera: su peruanidad integral y el poder de la Iglesia en la conformación de la nacionalidad peruana.

¿Dónde si no en su ser sacerdotal radica la clave de ese magnetismo ejercido entre los jóvenes? Así lo reconoce J. de la Riva Agüero: «Herrera es un hombre en toda la plenitud de su razón, que se desenvuelve dentro de un proceso lógico ascendente y regular [...] (A diferencia de Vidaurre). Herrera tuvo los ademanes del guerrero que con planta firme huella los baluartes que ha vencido, o el ímpetu de una cabalgata heroica que se encamina a escalar una cumbre» (1979: 226). Destaca en «el venerable e inesperado Bartolomé

5 Conviene consultar la reciente exhortación pontificia de Juan Pablo II Tertio millenio adveniente en la que el Papa sigue la corriente agustiniana del providencialismo histórico, de la que Bartolomé Herrera es un firme seguidor.

6 Con motivo del bicentenario de la Revolución Francesa, en 1989, han caído muchos de los viejos mitos acerca de este apasionante asunto. Tres de los más prestigiosos historiadores franceses P. Chaunu, J. de Viguerie, R. Sécher, dan la razón a Herrera, al señalar el saldo negativo del proceso. Vid. J.A. Gallego «La Revolución francesa, en sus interpretaciones». ACEPRENSA, Madrid, diciembre 1988, 189/88. 
JOSÉ ANTONIO BENITO RODRÍGUEZ

Herrera» una de sus más «entrañables devociones», "la viril desenvoltura, la fortaleza de temple teológico y precisa trabazón», declarando que «a pesar de que su cuerpo se encontraba enfermo ya, su labor de obispo no desmereció en nada de los que antes había realizado como maestro, político y diplomático. Emprendió saludables reformas en el clero y las costumbres de los fieles, pertenecientes a su diócesis, sobre todo continuó el trabajo de maestro en la formación de sabios y santos sacerdotes» (Riva Agüero 1935: 6 ss.).

Su personalidad es, por la altura de sus logros, la calidad de sus frutos, realmente excepcional. Estamos ante un hombre luchador, peleador, combativo. Su discípulo y amigo, Teodoro del Valle, quien pronunció la «oración fúnebre encomendada por la Cámara de Diputados» el 17 de septiembre de 1864 en la Catedral de Lima, condensará su vida con estas palabras: "Amó la sabiduría y la comunicó a otros. Predicó el bien sin avergonzarse; peleó, combatió por la verdad. Éste es su elogio».

Personaje polifacético: profesor, político (diputado, Ministro, Consejero), diplomático, periodista (director de El Católico escribe varios artículos polémicos en defensa de la religión, convirtiéndose en el bastión de la ortodoxia), apasionado en lograr la síntesis fe-cultura, rector de San Carlos, educador (siendo alumno dio clases), obispo, catequista, admirador de santo Toribio, amante de la Virgen, propagador de los Ejercicios de San Ignacio de Loyola.

\section{SACERDOTE TOTAL}

Me detengo en su dimensión sacerdotal porque me parece que es la auténtica clave de su coherencia, de su unidad de vida sin fisuras. El Siervo de Dios, Juan Pablo II, nos da un cabal retrato del sacerdote que nos ofrece Herrera: 
Es en el misterio de la Iglesia, como misterio de comunión trinitaria en tensión misionera, donde se manifiesta toda identidad cristiana y, por tanto, también la identidad específica del sacerdote y de su ministerio. En efecto, el presbítero, en virtud de la consagración que recibe con el sacramento del Orden, es enviado por el Padre, por medio de Jesucristo, con el cual, como Cabeza y Pastor de su pueblo, se configura de un modo especial para vivir y actuar con la fuerza del Espíritu Santo al servicio de la Iglesia y por la salvación del mundo. (Juan Pablo II N. 12)

En el Archivo Arzobispal de Lima (sección «Ordenaciones» Legajo 117: 18) se encuentran varios documentos testimoniales referidos al momento en que se dispone a ser ordenado sacerdote. La tónica general es el apremiante deseo del joven Herrera que solicita de sus autoridades el permiso correspondiente para ordenarse sacerdote. Salvando así, los 10 meses que le quedan para la edad reglamentaria de veinticinco años, según el Concilio de Trento. Se dirige al Rector de San Carlos, Dr. M.J. Pedemonte, así como a varios de sus compañeros para que le expidan «un documento que acredite mi buen comportamiento y regulares costumbres».

La petición de Herrera manifiesta:

[...] que si desde mis primeros años apetecí abrazar el estado eclesiástico por una de aquellas inclinaciones que mueven al hombre a obrar natural y casi necesariamente; luego que pude usar de mi razón de un modo menos imperfecto, este deseo ha venido a ser confirmado por serias meditaciones. Yo sé que Dios ayuda al que quiere cumplir sus deberes, por esto no me arredran las cargas del estado y el desprecio seguro de los pretendidos 
filósofos no me hace vacilar. Espero que VSY interesado como nadie en el aumento del clero, se dignará admitirme al examen sinodal y dispensarme de la edad (porque aun no he cumplido los 22 años) para recibir la orden sagrada del Diaconado, atendiendo a la falta de obispo y a otras circunstancias que no pueden ocultarse a su vista perspicaz por lo que suplico me conceda la gracia que solicito y prometo presentar las informaciones de estilo como también probar y extender la congrua ${ }^{7}$ que exigen los cánones.

La contestación de Mariano José Pedemonte, Rector del Convictorio de San Carlos, 5 de septiembre de 1829, nos ofrece una apreciación profética de nuestro protagonista:

Tengo la mayor satisfacción de verme precisado a acceder a la súplica del interesado. Es un joven cuyos pasos he seguido desde sus tiernos años en que ingresó a este convictorio y he admirado siempre una conducta superior a sus años y conforme al buen talento de que Dios le dotó y educación que recibió de sus padres. Ahora que anda en los 22 años de su edad, solicita entrar en el estado eclesiástico a que siempre ha aspirado y me prometo que la iglesia tendrá en él un sacerdote que edificará con su ejemplo e ilustrará con sus luces como lo vemos en este colegio en el que se halla de Maestro de Filosofía, matemáticas y Sagrada Teología y acreedor a obtener en él un empleo superior para el

7 Congrua: Renta estipulada por las sinodales de cada diócesis para el que se ha de ordenar in sacris. 
que necesita la mayor respetabilidad y la que conseguirá al menos con el sagrado orden del diaconado. Colegio S. Carlos.

Como testigo figura, en primer lugar, don José Dapelo, que certifica conocerlo a través del siguiente manifiesto:

Hace 6 años por ser ambos maestros en el Colegio de San Carlos que el suplicante es de buena vida y costumbres que es muy aplicado a los libros y estudios, que nunca ha estado casado ni menos con viuda de otro marido; que si pretende dejar el fuero secular no es por huir de ningún tribunal de justicia, ni porque le obligue a dar cuentas y legítimas pagas, sino por ser su vocación y últimamente que no tiene vínculo alguno ni impedimento canónico que le estorbe el servir los Sagrados Órdenes. Que todo lo dicho y declarado es público y notorio, pública voz y fama y la verdad en virtud del juramento hecho en que se afirmó y ratificó habiéndole leído esta su declaración que firmó con su señoría de que doy fe, José Dapelo.

El segundo testimonio ante el Notario Público, Esteban Iturriaga viene de don José María Sánchez Barba, al manifestar que:

Conoce al que lo presenta el tiempo de cuatro [años] con el motivo de entrar ambos en un mismo Colegio; que también conoce a sus padres los cuales son de limpia generación, sin raza de moros, judíos, herejes ni de los recién convertidos a Nuestra Santa Fe Católica; que el referido Herrera es de buena vida y costumbres, aplicado a los libros y estudios, que nunca ha sido 
casado y que no tiene vinculo ni impedimento canónico para servir los Sagrados órdenes.

El tercero es el de don José Bernardo Muñoz, alumno del colegio de San Carlos y con veintitrés años de edad, quien manifiesta que:

Conoce al que lo presenta el tiempo de diez años, con motivo de estar ambos en un mismo colegio; que el referido Herrera es de buena vida y costumbres, aplicado a los libros y estudios, que le conoce una verdadera vocación al estado sacerdotal; que nunca ha sido casado y que no viene vínculo alguno ni impedimento canónico para servir los sagrados órdenes.

Como conclusión de todo, el Dr. Espinoza manifiesta en Lima, el 25 de septiembre de 1829 , lo siguiente:

Vistos y en atención a que el contenido Doctor Bartolomé Herrera ha sido examinado y aprobado en el sínodo del examen que sufrió sobre latinidad y materias morales y teniéndose en consideración la urgente necesidad de Ministros Sagrados, que de la información producida y determinaciones hechas, resulta haber observado buena conducta, dispensándole los intersticios y extratémpora y los diez meses y quince días que le faltan para el cumplimiento de la edad legítima, admítase a las órdenes que solicita a título de la congrua que presenta y al efecto líbresele las respectivas dimisorias para el Ilmo. Y Reverendísimo Sr. D. José Calixto de Orihuela, dignísimo Obispo de la SIC del Cuzco para que SSIlma se sirva de conferir al expresado Don Bartolomé 
Herrera las órdenes de la primera tonsura clerical inclusive hasta el Sagrado Diaconado como lo pretende, inventándose en ella la partida de bautismo y este auto el que se le intimará a la parte reservándose el expediente en la Secretaría de este Gobierno Eclesiástico, Echagüe, Dr. Espinoza.

A continuación, se inserta la solicitud de ser recibido a examen de Teología Moral para recibir los Órdenes Sagrados del Presbiterado. La argumentación es bien sólida y contundente:

Que faltándome aún diez meses para los 25 años que requiere el Concilio de Trento y no pudiéndonos prometer con alguna seguridad que el YS Obispo de Cusco celebre órdenes el año venidero a causa de lo muy quebrantado de su salud, lo que me expone a sufrir gravísimos perjuicios, por lo que suplico se sirva dispensarme esta pequeña irregularidad, así lo espera Bartolomé Herrera.

El Edicto de Dimisorias, firmado por Francisco de Pascual y Erazo solicita el certificado de buena conducta al Obispo, representado en Juan Hernández, vicario Capitular. Quien certifica que conoce a los padres de don Bartolomé Herrera por cristianos y de buenas costumbres y que con arreglo a estos principios han educado al solicitante en la religión y en la literatura (Lima 22 de octubre de 1831).

Un día antes, el 21 de octubre de 1831, había solicitado nuevamente al Vicario Capitular para ser ordenado como presbítero y:

[...] habiendo confesado mi irregularidad que será de nueve meses de defecto de edad, el día en que se cumplan los edictos, 
me ha remitido a VSY mas yo espero confiadamente de la prudente bondad de VSY que considerando lo quebrantado de la salud del Ilmo. Sr. Obispo del Cusco y aunque esto no fuera, los atrasos que sufriría el Colegio de Huánuco, al hacer yo un nuevo viaje que paralizaría por segunda vez el estudio de la Filosofía y Matemáticas por el método de SC no concebirá poco motivada la dispensa que solicita.

Erazo y Tomás Arévalo firman el permiso:

atendiendo a las justas causas y motivos expresados por esta parte y a la necesidad en que se halla esta Iglesia para proveerse de sacerdotes que puedan desempeñar el carácter con las buenas luces y talentos de que se nos ha informado residen en el recurrente le dispensamos la edad de los diez meses y un día para que dé la Orden del Diaconado que obtiene pueden recibir la de Presbiterado en las Órdenes que van a celebrarse y se efectuarán para el mes de diciembre.

Por último:

[...] vistas y respecto a que del expediente consta ser el suplicante hijo legítimo, tener la dispensa de la falta de la edad [...] y haberse practicado las [...] informaciones de las que no ha resultado impedimento alguno sino más bien aparece haber observado buena vida y costumbres y haber sido aprobado en el examen sinodal, según parece de la certificación que antecede, teniendo consideración de la escasez de sacerdotes, admítase a las presentes órdenes a título de capellanía presentada y principalmente de 
ministerio y seso en la Doctrina que se le designase y al efecto pase al Venerable Cabildo para que si fuese de su agrado libre las respectivas dimisorias.

\section{OBISPO PARA LOS SACERDOTES}

$\mathrm{Al}$ conocer la noticia de su nombramiento a fines de 1859 , Herrera se resiste a aceptar el obispado. Había quedado vacante la diócesis de Arequipa al ser nominado Goyeneche para Lima, en sucesión de monseñor Pasquel. Para este puesto fue barajado el propio Herrera; él, sin embargo, había propuesto a monseñor Orueta, a la sazón obispo de Trujillo, quien había sido auxiliar de Pasquel y secretario de monseñor Arrieta y de Luna Pizarro. El Presidente Castilla se fijó en Herrera pero él se negó. El propio ministro de Relaciones Exteriores y Culto, Ortiz de Zevallos, fue a hablarle a nombre de Castilla, apelando a su patriotismo, pero no cedió. Acepta, al verse obligado por el propio Papa quien le conoció de cerca en su viaje por Europa, como enviado diplomático del gobierno de Echenique para preparar un Concordato entre Perú y el Vaticano. Estas fueron sus palabras: «Se me pide, en suma, el sacrificio de mi vida por la Iglesia. Lo haré porque he de contraerme absolutamente al cumplimiento de los deberes pastorales y mi salud está muy quebrantada».

Llegaron sus bulas de Roma y se preparó a conciencia para la consagración. Primero, pensó detenidamente cómo habría de proceder en el juramento. Sometió todo al parecer de su director espiritual, don José Mateo Aguilar, presentándose en palacio para jurar ante el presidente de la República. A continuación, practicó los Ejercicios Espirituales de San Ignacio, en absoluto silencio y completa soledad, durante ocho días. Por fin, en la Iglesia de San Pedro, de los PP. Jesuitas de Lima, el día de Pascua de 
Pentecostés, fue consagrado por su antiguo compañero y amigo, el Ilmo. Sr. don Francisco Orueta y Castrillón, obispo de Trujillo, y como concelebrantes el arcediano don Pedro Tordoya, obispo electo in partibus de Tiveriópolis, el Sr. Dr. don José Nicolás Garay, tesorero catedralicio (Acuerdos Capitulares 1855-1861 N. 21).

Antes de partir para su nuevo destino, pudo compartir sus vivencias y proyectos con el veterano obispo de Arequipa, José Sebastián de Goyeneche, quien entró como arzobispo de Lima el 14 de octubre de 1860. Herrera será uno de los obispos concelebrantes en la ceremonia de bienvenida (Acuerdos Capitulares 1855-1861 N. 21) al pastor que había regentado la diócesis de Arequipa por más de cincuenta años, el mismo que había propuesto años atrás ante la Santa Sede al celoso sacerdote como prelado.

Para Arequipa prepara una imprenta de su propiedad, ${ }^{8}$ arregló muebles para llevar al palacio episcopal, encargó un pontifical a Roma con báculo de plata sin dorar e introdujo el uso de las medias de lana sencilla para pontificar -en lugar de las de seda, usadas en América- tal como se prescribía en Roma. Compromete al célebre jesuita P. Luis María Bosco, para predicar una misión en Arequipa, ya que estaba resuelto a establecer en su nueva diócesis los Ejercicios del clero anualmente.

Tanto en la prensa limeña (El Comercio) como arequipeña ( $\mathrm{La}$ Bolsa), se da una cumplida crónica de la salida de Lima del Prelado. En ella se demuestra el aprecio en que se le tenía al obispo. Desde el día en que se supo en la capital que debía partir:

8 En la introducción a la Regla Consueta de la Santa Iglesia Catedral de Arequipa publicada en Arequipa, año de 1862, se incluye una carta de BH en la que confirma este hecho: «Está ya en Islay y pronto se trasladará a esta ciudad una imprenta que mandé traer de Lima. En ella haré que se imprima la Regla Consueta con esmerada corrección». 
[...] todos los amigos, todos los vecinos, todos los hombres de importancia se prepararon para tener el placer de acompañarlo en su salida para el puerto del Callao donde debía embarcarse en el «Amazonas» que S.E. el Presidente Castilla había puesto a su disposición. Partió entre las más vivas expresiones de dolor y de sentimiento de los habitantes de Lima al ver que se separaba de entre ellos tal vez para siempre un paisano, un amigo, un hijo ilustre de la Capital. En el Callado se le ofreció un gran almuerzo tanto para él como para su comitiva en casa del señor Dulauto. A las seis de la tarde, tras las tiernas despedidas del Ministro de Guerra General Pezet, de sus discípulos, amigos y allegados, se inició el viaje.

Durante la travesía fue muy bien tratado por el Comandante de la Fragata don Francisco Sanz que había sido discípulo suyo. Llegó al puerto de Islay en la mañana del primero de enero a las seis de la mañana. A pesar de la hora, todos los vecinos se hallaban en el muelle y con las demostraciones más expresivas de respeto, amor y veneración. Lo condujeron a la Iglesia, antes de entrar a la casa-hospicio que le había preparado el párroco de Tambo don Pedro José Quirós. Allí, en el Templo del Señor, rodeado de la multitud, postrado en tierra y lleno de la más dulce ternura, dio gracias al Omnipotente por su feliz arribo y porque le hacía entrar en el rebaño de las ovejas que le estaban ya encomendadas. Celebró, además, el Santo Sacrificio de la Misa con toda la solemnidad posible. Regresó a casa donde permaneció hasta el jueves ocho colmado de todas las atenciones de las autoridades y vecinos y felicitado por una comisión que había partido desde Arequipa. Se le cantó una Misa de gracias con Te Deum, confirmando al día siguiente a su llegada a más de 200 personas. Salió a las once, almorzó en el tambo de 
JOSÉ ANTONIO BENITO RODRÍGUEZ

Guerreros y continuó hasta la Joya donde comió y durmió, siendo recibido por el cura de Sachaca, Domingo Neyra. El 4, tras el almuerzo, prosiguió hasta la Jara, donde descansó una hora para continuar el camino a Lloqueo. Aquí fue hospedado por el cura coadjutor y el encargado del cura propio de Cayma, Lorenzo Julián Arróspide. El 5 de enero, tras el almuerzo, caminó hasta Tiabaya donde entró a las cuatro de la tarde, tras descansar una hora en el Cortaderal hasta donde vinieron algunos eclesiásticos y un piquete de caballería mandado por el señor Prefecto para ponerlo a sus órdenes. Más adelante, se presentó el señor Subprefecto en compañía de muchos señores y sucesivamente fueron apareciendo varios grupos de personas.

Antes de entrar a Congata, la primera demostración del pueblo que conmovió bastante a su señoría, hasta el extremo de llorar de ternura, fue la presencia de varios vecinos pobres y sencillos que habían ido a pie y levantado un arco campestre que manifestaba, a su modo, el entusiasmo y amor al que estuvieron animados. Al entrar en Tiabaya fue cuando se desbordó el pueblo en entusiasmo religioso hacia el prelado, por las expresiones de afecto y ternura, el adorno y obeliscos de sus calles, el ruido de los cohetes y campanas, la abundancia de flores y de ramos que derramaban por el tránsito y más que todo en las felicitaciones que personalmente le hicieron en la casa del señor cura, don Mariano Idiaguez García, quien le invitó a almorzar. Allá el Señor Chantre, Teodoro Leyva, como portavoz del Cabildo Eclesiástico le felicitó y recibió con una alocución bastante enérgica y expresiva

a la que contestó nuestro Dignísimo Prelado con el tino y sabiduría que le son característicos, manifestando los grandes y verdaderos deseos que le animan en favor de su diócesis y de sus ovejas que dependen de su celo pastoral para conseguir su salvación a la que encaminarlos, confiando para conseguirlo como buen católico en las luces y protección del cielo. 


\subsection{Entrada en Arequipa9}

El periodista y coronel de Infantería, Pedro de Vidaurre, describe la entrada del Prelado en Arequipa. Comienza por señalar la grandeza de Arequipa y su gran prelado Goyeneche. Describe a Herrera en quien destaca su producción literaria, y su carrera jurídica en el Convictorio San Carlos. Destaca también su patriotismo y su valoración de España, como de la civilización incaica. El 6 de enero, día de Reyes, a la una de la tarde llegó el obispo -número 22 según el cómputo de S. Martínez- a la Recepción preparada en la Banda, acompañado de numeroso concurso de notables y gran masa de pueblo que le seguía con aplausos y todo género de manifestaciones de júbilo y veneración. En aquel local recibió las felicitaciones y visitas de las corporaciones y notables del país que fueron a besar el anillo del nuevo prelado. Le acompañaron el Jefe político del departamento, las autoridades civiles, los notables, los representantes municipales que lo llevan desde las puertas o muros de la ciudad bajo palio hasta la Catedral. El ejército que sostiene la religión del Estado por las ordenanzas generales y por la constitución política presenta las armas al nuevo jefe de la iglesia y tocan las músicas la marcha triunfal de la Águila de los Césares. Tantos honores les parecieron excesivos a los redactores de La Bolsa en un suplemento publicado en el mismo periódico titulado «Cuatro preguntas sueltas a quien corresponda» y que firma «Un preguntón». A las 4 de la tarde, revestido con capa pluvial y bonete, bajo palio entró en la Catedral. Ya dentro, Monseñor, revestido de pontifical, se cantó un Te Deum, se elevaron preces a Dios y se leyó en alta voz la Pastoral del nuevo obispo. Desde allí pasaron al palacio

9 Archivo Arzobispal de Arequipa, Actas Capitulares, Libro VI. «El 6 de enero del presente año hizo su entrada pública en esta ciudad el Ilmo. Sr. Obispo Dr. D. Bartolomé Herrera con todas las prevenciones y aparato que son de costumbre». 
episcopal ${ }^{10}$ donde recibió muestras de adhesión hasta las diez de la noche, hora en que terminó el refresco preparado por el Cabildo. El 7 de enero tuvo lugar la misa de acción de gracias pontificada por el Sr. Obispo y a la que acudieron autoridades, corporaciones y el pueblo fiel. Al final, se retiró la comitiva hasta el Colegio Seminario donde "peroró a los alumnos con expresiones que congratularon a todo el auditorio, pasando en seguida a su palacio, donde recibió las palabras de los colegiales de seminaristas y del colegio San Francisco, así como las felicitaciones de los sacerdotes». A continuación visitó a la primera autoridad política del Departamento. Por la tarde se ofreció un nuevo banquete. Parece ser que también los monasterios y autoridades ofrecieron parecidos agasajos al nuevo prelado.

\subsection{UN AMBICIOSO PROGRAMA}

En su primera pastoral -firmada en Lima, el 15 de diciembre de 1860queda diseñado un ambicioso programa. Esta fue leída a los fieles con motivo de su entrada oficial. A continuación se detallan algunos puntos:

a) De la ausencia del gran prelado Goyeneche tras cuarenta años de obispo en Arequipa: «¿cómo no han de experimentar, sin embargo, vuestros corazones la dolorosa angustia del hijo que se separa del padre, para no verlo más durante la vida presente con sus ojos de carne? ¿Qué sacerdote no ha recibido de él su orden sagrado? ¿Quién

10 Según el P. V. Barriga fue obra de Mons. Jacinto Aguado y Chacón hacia 1750: «Hizo construir el Palacio del Buen Retiro, hoy Seminario, que lo dejó para Palacio Episcopal de sus sucesores, con todo lo que contenía, entre ellos una buena colección de cuadros de óleo, como consta en el inventario de donación» (1952: 281). 
no ha crecido bajo las bendiciones que ha estado derramado más de cuarenta años en Arequipa?».

b) Sus deseos de paz en medio de tanta angustia nacional: «En vuestras angustiosas circunstancias, venimos, enviados por Dios y por la Iglesia a traeros la paz y el consuelo de lo alto; venidos con la misma abundancia de bendición del Evangelio de Cristo que hallabais en vuestro Pastor antiguo. Pero nuestras manos cargadas de los dones de la divina misericordia tiemblan junto con todo nuestro ser, por es espanto que nos inspira la miseria y la indignidad de nuestra persona».

c) Su amor incondicional a la Iglesia, la infalibilidad del Papa y su primacía universal: «Pero, si cuando se presenta algún suceso interesante en el orden político, vuestro corazón no puede permanecer encerrado en los estrechos límites de vuestros departamentos sino que se dilata por toda la República, palpita de amor a la patria, se ufana contemplándola a pesar de sus desgracias y hasta se abandona delirios de felicidad y grandeza que pronto se cambian en dolorosos desengaños ¿hasta dónde no habrá de ir vuestro corazón en los momentos en que recibís las primeras palabras del nuevo Pastor de vuestras almas? ¿Cuál no deberá ser el enardecimiento de vuestro amor a la Iglesia que os lo manda? ‘a la Gran Patria a que pertenecéis por el bautismo? Esa Patria no tiene otros límites en el mundo que los del mundo. Su existencia temporal no acabará sino cuando el tiempo acabe y aun entonces seguirá existiendo bajo una forma inmortal. Ninguna sociedad humana puede darnos los bienes que ella nos da desde ahora, ni hacernos las promesas que nos hace ella y que, lo sabéis, son 
infalibles. A ninguna pertenecemos tan entera y completamente, con todo nuestro ser, como a ella. Ninguna sino ella satisface los delicados y más escondidos sentimientos del corazón y sus nobles tendencias. En ella y no (sic) parece imagen cabal de la divinidad. Sus ciudadanos son los únicos hombres libres de la tierra porque son los únicos que solo obedecen a Dios. Cuando las potestades del mundo, que no saben lo que tienen en sí de divino, piensan que la ejemplar obediencia cristiana se refiere, en lo temporal mismo, al poder humano, se engañan. Para los hijos de la Iglesia no hay nunca otro imperante ni otro Señor que Jesucristo».

Les habla de las grandes dificultades por las que está atravesando y se dirige a las fuerzas vivas, clero secular (desde su dedicación a los seminaristas) y regular, contemplativas y pueblo fiel, comprometiéndose con todos ellos hasta el final de sus días:

Con estos socorros, y con los de la Divina gracia, ante todo, vamos a trabajar en vuestra salvación, queridos fieles de nuestra Diócesis. Nuestra inteligencia, nuestro corazón, nuestras fuerzas os pertenecen por entero. No queremos tener, Dios lo sabe, y mediante su ayuda no tendremos pensamiento, deseo ni acción que no se dirija a vuestra salud y a la honra del Señor. Vivimos solo para vosotros $\mathrm{y}$, después de pasar en medio de vosotros y en vuestro servicio espiritual el resto de nuestros días, nuestras cenizas descansarán confundidas con las vuestras. Habéis padecido y padecéis grandes calamidades: pero carísimos, nos os sorprendáis con el fuego de la tribulación, que es para prueba vuestra. Sed prudentes y velad en oraciones. Y, ante todas las 
cosas, teniendo entre vosotros mismos constante caridad, porque de la caridad cubre la muchedumbre de los pecados.

\subsection{SU DESEO DE REFORMA}

Su normativa se rige por las máximas de santo Toribio Mogrovejo y San Francisco de Sales. Se miraba también en las heroicas virtudes de San Gregorio VII y santo Tomás de Canterbury, dispuesto a subir al cadalso en defensa de los derechos de la Iglesia. Se propuso la reforma del clero secular y regular, particularmente el femenino. Se empeñó en el establecimiento de la Compañía de Jesús en Arequipa, al igual que los franciscanos.

Tal como proyectó, se dieron los Ejercicios al clero por parte del P. Bosco, a quien encomendó un completo y duradero curso misional en la ciudad. Simultáneamente cuidó que en su Palacio Episcopal se llevase un régimen de vida espiritual sustentada en la oración mental, la lectura espiritual y el Santo Rosario. No dejó de celebrar un solo día la Santa Misa; colaboró en la tarea el citado P. Bosco.

\section{4 SU «REGALADO REFRIGERIO»}

Desde su primera pastoral dejará constancia de la predilección que siente por el Seminario: «Muy regalado refrigerio nos prometemos, por otra parte, en nuestro Seminario, cultivando hasta donde nos fuere dado con nuestras propias manos las hermosas esperanzas de la Iglesia».

Visitaba a diario el Seminario y casi siempre a caballo, pues sus dolencias no le permitían hacerlo de otro modo. Según M.A. Cateriano dotó competentemente las cátedras, introdujo reformas, mejoró el local con la construcción de grandes salones en los altos. Su trato con los alumnos 
era afectuoso y franco, cuidando de que fuesen bien tratados en la mesa. $\mathrm{Su}$ asistencia a los exámenes era constante, permaneciendo en ellos varias horas. Elaboró personalmente alguno de los programas y currículos de algunas materias como Metafísica y Teología. Conocemos los programas y tratados de Lógica (según el sistema escolástico y de acuerdo con lo programado en Jauja en 1857) y Teodicea (con argumentos precisos y concluyentes sobre la existencia de Dios y sus atributos divinos) redactados por el propio prelado para sus alumnos del Seminario. ${ }^{11}$

Redactó, además, un texto nuevo de Estética. Otras veces potenciaba un buen texto como el de Filosofía del P. Tergiordi, en detrimento de Liberatore, por su mayor claridad y precisión. Desde que él llegó, tal como se había propuesto en su Pastoral, tomó el Seminario bajo su inmediata dirección. Conservó como rector al benemérito Sr. Forgas y como vicerrector escoge al joven seglar, Nicanor Porcel, que llegará a ser Deán de la Catedral y Vicerrector de la UNSA. Enseñó filosofía en el Seminario. Celebró Órdenes y concurso de curatos, refaccionó el Palacio del Buen Retiro e impulsó la imprenta del Seminario. Donó mil soles para Pío IX quien había sido despojado de los Estados Pontificios. Se guarda en la correspondencia las aportaciones voluntarias del pueblo fiel de toda la diócesis que, motivados por su prelado, colaboraron a la noble causa de ayudar al Papa (Martínez 1933)..$^{12}$

11 Al menos en la Biblioteca de la Recoleta se guardan el Tratado de Lógica, redactado por el obispo Dr. BH para el uso del Seminario Conciliar de San Jerónimo de Arequipa. Imprenta del Seminario, 1873, y el Tratado de Teodicea de 1872.

12 S. Martínez: Historia de la Diócesis de Arequipa y sus obispos. Arequipa, 1933. 


\subsection{Traslado a la Catedral}

El 1 de diciembre de 1844 un pavoroso incendio consumió ornamentos y reliquias, que hizo necesaria la refacción tal como en la actualidad se contempla. El 3 de enero de 1845 se nombró una Junta Reconstructora por parte del Gobierno del General Castilla y que estaba integrada por el Prefecto, Pedro Cisneros, el Sr. Obispo, Goyeneche; como presidente y vicepresidente respectivamente. Como vocales figuran el tesorero de la catedral, Mariano Masías, canónigo JGV, Rector del Colegio de las Educandas, Fernando Arce y Fierro; Juan de Dios Salazar y Juan Sardá; se añadieron Juan Mariano Goyeneche y el clérigo Mariano Escobedo. En cuanto llegó el Prelado a nuestra ciudad, se apresuró a culminar el templo mayor. El 20 de julio de 1861 el Cabildo avisó al Prefecto que la Catedral estaba lista para poder celebrar los cultos. Un Jueves Santo predicó en ella un gran sermón sobre la caridad. Defendió las prerrogativas y práctica de la Iglesia contra los decretos del Ministro de Culto quien quiso imponer de Canónigo Magistral a un señor sin previo concurso.

5.6 Como complemento a su acción formativa del Seminario, SE DEDICARÁ CON AHÍNCO A LA INSTRUCCIÓN DEL CLERO

$\mathrm{Al}$ segundo año de su episcopado, 1862, celebró concurso para la provisión de curatos; en el mismo, tuvo mucha labor para medir las aptitudes de los opositores, que en su mayor parte le eran desconocidos, ya para apreciar sus merecimientos. Conocemos un Decreto del 14 de noviembre de 1863, por el que recuerda al Comendador de la Merced de Arequipa, que siendo uno de los examinadores sinodales, se espera concurra puntualmente para estar en el tribunal de los opositores al concurso de curatos (AMA, XVII, p.112). 
Sabemos que solo ordenó cuatro sacerdotes en su tiempo de obispo; actitud que recuerda, entre otras, la de Ignacio de Loyola, quien afirmaba que tan solo pedía vivir para lograr una buena selección entre los jóvenes candidatos a la Compañía de Jesús. Sus biógrafos G. y R. Herrera citan unas palabras pronunciadas por el propio protagonista pocos días antes de su partida para la vida eterna:

Que en los cuatro años corridos desde su consagración episcopal no había ordenado de sacerdotes sino a cuatro; que no le pesaba haber sido tan parco, que había probado antes muy prolijamente su vocación, así como su virtud y su ciencia; porque, el mayor mal que un obispo puede hacer a la Iglesia y a la sociedad es lanzar en ella un clero ignorante; pues el sacerdote es guía, y sin ciencia ¿cómo podrá guiarse a las almas? La ciencia sirve al sacerdote hasta para volver al buen camino si por desgracia se extravía.

Su primer edicto para la convocatoria de órdenes en 1861 insta a los candidatos que no se acerquen los que no se sientan dispuestos a padecer martirio en los tiempos recios que les tocó vivir:

Cuán tremenda situación será la de un prelado al comparecer en el terrible tribunal de Dios cuando se a interrogado acerca de las funestas consecuencias, de los daños irreparables que ocasionará ordenando sacerdotes a sujetos indignos de tan delicado y santo ministerio que pide celo infatigable, renuncia absoluta de sí mismo, instrucción incesante, ejemplos diarios de virtudes cristianas ¿Cómo reparar tan graves daños? ¡Alma por alma! 
Aparece bien claro en otra circular de 1861 en el que manifiesta:

Siendo necesario que estén habilitados los sacerdotes idóneos, no solo para celebrar sino también para administrar el sacramento de la penitencia, encargo a VP haga saber a los de esa comunidad que no tengan expedidas sus licencias, bien porque no los hayan pedido después de mi toma de posesión del obispado, bien porque hayan concluido el término por el que mi Vicario los hubieses concedido que deben presentar sus solicitudes en el término de un mes contado desde hoy Bte. Ob.

En 1863, 5 de febrero, puede anunciar el Vicario Pedro de la Flor que el Sr. Obispo dispuso la creación de una clase de Teología moral y que no solo comprenda al clero secular, sino a los coristas de los conventos donde no haya enseñanza a fin de que tengan este auxilio para instruirse fácilmente y de que la pereza quede excusa (AMA, XVII, p.83).

Al igual que practicaba en Lima con sus mejores discípulos, futuros miembros de la Unión Católica, reúne en su Palacio a los notables de Arequipa para conversar acerca de la cultura y la fe, saliendo al paso de las doctrinas opuestas a la fe y que estaban de moda en ese tiempo: el jansenismo, galicanismo y regalismo. Como libro de texto seguía el célebre «Catecismo de perseverancia» del P. Gaume.

\subsection{A Mayor gloria de Dios}

Fue la divisa de su vida, especialmente tras la práctica de los Ejercicios Espirituales. Por ello -tal como señalan sus biógrafos- buscaba el dictamen ajeno con frecuencia y se hacía aconsejar para seguir las consignas de San Ignacio de Loyola de no determinarse por capricho propio sino seguir 
siempre, en todo, la voluntad divina, lo más perfecto, la mayor gloria de Dios. J. B. Leguía remarca su obsesión por la obra bien hecha y cómo se valía hasta del confesonario para enseñar a hablar correctamente el castellano; era un educador, realista, que sabía que los valores espirituales, debían apoyarse en unos valores humanos. Quiso y -en parte lo consiguió- el mejor yo de sus alumnos para que lo pusiesen al servicio de Dios y de la Patria. Así lo hizo él de forma ejemplar.

Los medios de santificación eran la oración y la lectura espiritual. Su palacio era una especie de monasterio, sin tufos de cucufatería, pues era al mismo tiempo un centro social «en frecuente comercio con sus fieles» para conservar la pureza de la fe y la religiosidad.

Tuvo siempre una delicadeza especial con los sacerdotes. Se manifiesta en su actitud indulgente y misericordiosa hacia un religioso, Fr. José Ascensio del Mar, a quien le concede prórroga por cuatro meses de sus licencias de celebrar, predicar y confesar a fecha de 20 de julio de 1861 para que use de ello en Ilabaya donde ahora s necesario su servicio (AMA XVII 1861: 83).

En cuanto restauró el Palacio del Buen Retiro, futuro seminario, ubicado en la actualidad en la esquina de la Av. Goyeneche con la calle Santa Rosa, lo amuebló decentemente, pero sin lujos, y comenzó a vivir con su equipo y familia. Su idea era -como posteriormente se hará- trasladar allí el Seminario - ubicado en la calle San Francisco, en el actual Banco Continental-y el palacio al Seminario por su mayor extensión y tener tierras de labor. La acción le correspondió a un predilecto discípulo de Herrera, José Ambrosio Huerta, el 26 de abril de 1882.

$\mathrm{Su}$ primer baño en el fervor de las masas lo tuvo al acercarse a la Ciudad Blanca, tras recorrer muchos de los poblados de la diócesis. Muy 
pronto, le tocó organizar la colecta en favor del Papa Pío IX, expulsado de los estados pontificios. Se guarda en el Archivo Arzobispal la relación nominal con las pequeñas limosnas de todos los fieles de la sierra y de la costa de Arequipa. Finalmente, el prelado llegó a donar mil soles.

A ellos se dirige el 28 de enero de 1861. Circular a los párrocos pidiéndoles oraciones y una colecta en beneficio del Papa Pío IX arrojado de los Estados Pontificios:

En tan aflictiva situación, aun sin precepto ninguno de nuestra parte, consideramos las rogativas, una necesidad de cada corazón católico; no las rogativas de pocos días y de algunos momentos cada día, sino de todos los días y de todos los momentos. La Santa Misa de nuestros sacerdotes, las preces del Coro de nuestro Venerable Cabildo y de las Comunidades religiosas de uno y otro sexo; el Santo Rosario, que esperamos no se omitirá ninguna noche en el seno de las piadosas familias que forman nuestra Diócesis; la oración en común y la oración privada; todas las obras de misericordia de cualquier género, que ejerzamos con nuestros prójimos; en fin, todo acto meritorio, se debe ofrecer a Dios como un ruego fervoroso, para que abrevie los días de prueba que estamos atravesando, para que acepte en bien del mundo el martirio prolijo que sufre el Sumo Pontífice y la Iglesia y para que derrame sobre él y ella el consuelo [...].

\subsection{SU ENTREGA GENEROSA}

Dice Cateriano: «Para el Señor Herrera no habían horas limitadas de despacho ni días en que no estuviera visible sin necesidad de hacer antesalas 
ni de esperar a ser anunciados. A todos oía con esa natural afabilidad y sencilla bondad que le eran características y, como su percepción era tan rápida, se hacía al instante cargo del asunto propuesto y, considerándolo en sus distintas facetas le daba pronta, fácil y acertada solución». Se ve palmariamente en su «Circular sobre el terremoto del 30 de junio de 1863»:

Los dos terremotos de anoche, con los numerosos ruidos subterráneos que se oyen todavía, parecen voces repetidas por ecos prolongados que el Señor dirige a nuestros corazones para que imploremos su misericordia en espíritu de verdadera penitencia, con la oración y con santas obras. El pueblo fiel que con razón se halla tan conmovido espera, sin duda, que de alguna manera lo edifiquen el clero y las personas religiosas. Creo, pues, oportuno que, por ocho días, en mi Catedral y en todas las iglesias en que se reza en coro el oficio divino, se recite después de nona o de la misa si se adelantaren horas, la letanía de los santos y las siguientes oraciones en la forma de los días de rogativa. Los que rezan privadamente convendrá que hagan lo mismo después de laudes o en el tiempo que les fuese más cómodo. Tengan presente los sacerdotes, se lo encargo a cada uno por las entrañas de Nuestro Señor Jesucristo que han recibido su orden sagrada solo para salvar las almas, que el Señor les ha de pedir estrecha cuenta de los que por descuido de ellos se pierdan y que en los momentos actuales deben mostrarse más llenos de caridad que nunca para recibir en el confesonario a los que a Él se acerquen y para atraer a Él a todos los necesitados. Dios guarde a ustedes. Bartolomé, Ob. de Arequipa. 


\subsection{CUIDADO POR LA LITURGIA}

Es evidente esta preocupación por la circular sobre el alumbrado en la iglesia:

Palacio Episcopal de San Juan Nepomuceno del Buen Retiro de Arequipa, 4 de abril de 1862: Circular a los Prelados de los Conventos. En el Añalejo del clero secular para el presente año, se ha publicado por mi orden expresa un Decreto de la Sagrada Congregación de Ritos, que dispone que el alumbrado de las iglesias sea de cera pura como lo previenen las rúbricas y dicho Decreto está acompañado del Comentario hecho por el Maestro de Ceremonias apostólicos. Su tenor es el siguiente [en latín...] El Maestro de Ceremonias Apostólico Pío Martinucci comenta la anterior decisión en los siguientes términos: [en latín]. Lo comunico a VP por exigirlo así el grave deber que me imponen los cánones de velar sobre la fiel observancia de la Sagrada Liturgia y de extirpar las corruptelas que en materia de tanta importancia se introduzcan contra las reglas y contra el espíritu de la Iglesia. Espero que VP cuidará de su exacto cumplimiento y de que no se permita a los fieles colocar en los altares velas que no sean de cera pura. Nada importará que en las fiestas haya menos luces, con tal que el culto sea conforme a los inviolables mandatos de la Iglesia. Dios guarde a V.P. Bartolomé, Obispo de Arequipa. (AMA, Varios-1, p.27) 


\section{ENFERMEDAD Y ÚLTIMAS VOLUNTADES}

Se retiró a Cayma a aspirar el aire puro del recoleto poblado arequipeño. De aquí pasó a Yanaguara. Queda constancia de su enfermedad por la carta de 4 de diciembre de 1862:

«Habiéndonos precisado el mal estado de nuestra salud a retirarnos al campo y a prescindir de toda tarea mental, venimos a encargar y encargamos del Gobierno de la Diócesis a nuestro Provisor y Vicario General Dr. D. Pedro de la Flor al cual transmitimos toda la jurisdicción necesaria y que por derecho podemos transmitirle, mientras recobremos, si el Señor fuere servido las fuerzas que habemos menester, para desempeño personal de nuestros pastorales deberes. Lo que comunico a Usted para su inteligencia y fines consiguientes». (Fdo. Pedro de la Flor).

Uno de sus biógrafos, Mons. García y Sanz, testimoniará:

A pesar de la enfermedad del pulmón que, desde años atrás, lo afligía y quebrantaba sus fuerzas, renueva en su diócesis el espíritu de los Toribios; recorre una parte de ella corrigiendo sus costumbres y administrándole los santos sacramentos; le hace oír con frecuencia su inspirada palabra y es el consuelo de los afligidos y el alivio de la indigencia de innumerables familias. (García y Sanz 1879: 294-295) 
El 4 de agosto de 1864 volvió al Palacio del Buen Retiro; el 8 otorgó su testamento. Hay que destacar en él mismo su preocupación por manifestar su impertérrita ortodoxia, explicitando que "Quiero asimismo que se sepa que en medio de mis miserias jamás he pertenecido a Sociedad alguna Secreta que las he condenado, condeno y condenaré siempre todas, como las tiene condenadas la Iglesia». Confiesa no haber adquirido ningún bien en el tiempo que gobernó la diócesis. Tendrá un recuerdo especial para los lugares en los que ejerció cura de almas como la docencia:

Declaro que fui cura de Cajacay y dejo a aquel curato por vía de legado la suma de 2000 pesos, para que se inviertan en ornamentos sagrados a beneficio de sus iglesias en esta forma: 1000 pesos para la iglesia de Cajacay, 800 para la de Chancayan y los doscientos restantes para la de Ruquia, sin que las iglesias de los otros tres pueblos puedan exigir nada.

Declaro que también fui cura de Lurín y es mi voluntad dejar a ese curato 1200 pesos, también para sus ornamentos y fábrica de la iglesia, aplicándose 800 pesos a la de Lurín y 400 a la de Pachacamac.

Declaro que fui canónigo y después chantre de la Iglesia catedral de Lima. Dejo a la fábrica de dicha iglesia la cantidad de 300 pesos por una sola vez.

Declaro que fui Rector del Colegio de S. Carlos, cerca de 10 años, en cuyo tiempo procuré corresponder con todas mis fuerzas al beneficio de la educación; emplear los expresados 10 000 pesos en la iglesia de San Carlos.

Declaro que poseo en la ciudad de Lima una capellanía lega fundada en todo el valor de una casa sita en la cuadra de la pileta 
de San Bartolomé; la cual debe pasar después de mi fallecimiento a la congregación de seglares de Nuestra Señora de la O.

Declaro que como chantre de la Iglesia catedral de Lima administré la Obra Pía fundada por Laja en favor de españoles pobres y ancianos y aunque el fundador dispone que el cobrador forme para sí una muy módica remuneración. Desea «asegurar su subsistencia a mi tía la señora Doña Mercedes Vélez» a la que deja bienes sustanciosos.

Mando que se celebren 5000 misas por mi intención. Mando que a mi sirviente Teresa Ríos, cuyo cariño para conmigo y mi fin nunca agradeceré bastante, se le den mil pesos en case de legado y por una sola vez. Otra igual cantidad de mil pesos se entregarán también a Gervasio Medina.

Recuerda por último a los personajes más cercanos como albaceas: Sr. Cura de Santa Ana de Lima, Dr. D. Manuel Teodoro del Valle y a D. Manuel Fernando Gálvez. mancomunadamente, y para los arreglos que fueran precisos en esta ciudad de Arequipa, al Sr. Maestrescuela Dr. D. Pedro de la Flor. Sus familiares: Da. Duria Herrera y Ccurto y sus hermanos D. Mario, D. Rodrigo, D. Teodosio, Da. Delfina, Da. Victoria, Da. Julia y Da. Teodora Herrera y Curto Recuerda se paguen las deudas de Tapia, del Seminario y de la Iglesia de Quilca, no deben pagarse sino con la renta de la Mitra. El Dr. San Martín que lo asistía había expresado la tarde del nueve el pronóstico de su muerte. El 10 estuvo acompañado de personas respetables y del clero, canónigos, mientras recibió el Viático. [El resalte es nuestro]

A poco más de las cuatro de la tarde se halló solo con su confesor el presbítero don José Quintanilla y extendiendo los brazos, dándole las 
gracias por sus cuidados, expiró. Veinticinco campanadas de la campana mayor avisaban al pueblo fiel mistiano que su Pastor cruzaba el umbral de la eternidad y se encontraba con su Dios para siempre. Contaba tan solo cincuenta y seis años de edad. «Así terminó la vida del ilustre Obispo de Arequipa, del hombre de razón más clara, talento más ordenado y percepción más rápida de que pueda gloriarse el clero contemporáneo del Perú»(Cateriano 1908: 242 ).

Teodoro del Valle en su oración fúnebre dijo que «un pueblo sin historia es un huérfano; una nación sin tradiciones es un expósito». El epílogo de la vida del Obispo de Arequipa está cifrado en estas tres palabras: ciencia, patria, religión; si queréis: sabiduría en el hombre, justicia en la tierra, Dios en todo.

En Arequipa se le hicieron solemnes exequias, en las que predicó el P. Núñez. En su querido templo de San Carlos, anexo al Convictorio, se le tributaron honores fúnebres. El elogio corrió a cargo de D. Juan Ambrosio Huerta, rector del seminario y más tarde obispo de Puno y Arequipa.

Gustavo Quintanilla Paulet en varios artículos publicados en el diario mistiano El Deber concluye: «El patriotismo vivo, como toda la vida, tiende a comunicarse... Había comprendido que el Perú no va a engrandecerse por un hombre, sino por generaciones siempre jóvenes y siempre desprendidas».

\section{CONCLUSIÓN}

Campea por toda la vida y obra de Herrera el firme deseo de hacer el bien a los demás, de reformar la sociedad, a través de la educación. Su corazón sacerdotal fue el manantial del que brotó su acción formativa. Como docente, a través de su responsabilidad en el gobierno en cargos directivos, en la 
parroquia, en la diócesis, en la tribuna política y en la prensa, en el púlpito y el altar, «tuvo la fuerte convicción de haber recibido una especial misión de Dios para realizar una reforma de la sociedad peruana de su época... Luchó por lograr unos objetivos concretos y perfectamente determinados: moralizar la sociedad, combatir el liberalismo — que se presentaba como enemigo de la religión-y preservar los valores cristianos» (Putman 1879: 294-295). En parte lo logró, especialmente cuando estuvo al frente del Convictorio de San Carlos, el cual llegó a tener un gran prestigio en todo Sudamérica, y del cual salieron hombres ilustres que estuvieron al frente de las principales instituciones del país. Como enfatiza Jorge Putnam: «Herrera sabía que para moralizar el país había que empezar por la reforma educativa, y es lo que comenzó a realizar en San Carlos» (Putman 1879: 294-295). Cierto que esa profunda renovación social que él deseaba quedó a medias por no encontrar a nadie que la continuase con la misma fuerza e interés con que él la promovió, pero siempre quedará como paradigma de lo que puede un educador, un maestro, cuando tiene ideas claras, convicciones profundas, corazón generoso. Él comenzó su actuación pública con aquel famoso sermón en las exequias del presidente Agustín Gamarra, en 1842. Desde entonces se granjeó la fama de gran orador y pensador profundo. Luego, le vino la década como Rector del Convictorio de San Carlos, el cargo de ministro de varias carteras durante los gobiernos de Echenique y Castilla y hasta llegó a ser Presidente del Congreso de la República. ${ }^{13}$ Desde esos cargos Herrera promovió una gran reforma educativa, social y moral. Pero su prematura muerte, en 1864, siendo obispo de Arequipa, truncó esos grandes ideales y no se llegó a realizar toda la reforma que él proponía.

13 Debe notarse que en esa época estaba permitido que algunos sacerdotes, con especiales cualidades, interviniesen en política, trabajando por el bien común de la patria. 
Con el Papa Francisco, en su encíclica Lumen fidei, podemos concluir en Monseñor Bartolomé Herrera: «¡Cuántos beneficios ha aportado la mirada de la fe a la ciudad de los hombres para contribuir a su vida común! [...]. La fe ilumina la vida en sociedad; poniendo todos los acontecimientos en relación con el origen y el destino de todo en el Padre que nos ama, los ilumina con una luz creativa en cada nuevo momento de la historia» (N. 55). Su mirada luminosa y su corazón ardiente supieron suscitar centenares de líderes en la cátedra, en la política, en el altar, en el corazón de la sociedad peruana desde su indesmayable y permanente pasión de educar. 


\section{BIBLIOGRAFÍA}

Altuve-Febres Lores, Fernán (comp.)

2010

Bartolomé Herrera y su tiempo (Actas del congreso conmemorativo del bicentenario del natalicio de Bartolomé Herrera 1808-2008). Lima: Sociedad Peruana de Historia/ Editorial Quinto Reino, pp. 35-54.

Archivo del Convento de la Merced de Arequipa (AMA)

1861

Legajo XVII, p. 112.

Archivo del Cabildo de la Catedral de Lima

1855-1861 Acuerdos Capitulares, N. 21, p. 200.

BARREnechea, Oscar

1947

Bartolomé Herrera. Educador y diplomático peruano. Buenos Aires: Peuser.

BARRIGA, Víctor

1952

Memorias para la historia de Arequipa. Vol. IV. Arequipa: Editorial La Colmena.

Benito Rodríguez, José Antonio

2001

«Bartolomé Herrera, Maestro del Perú, Obispo de Arequipa». En Revista del Archivo Arzobispal de Arequipa, N. 5, Arequipa, pp.79-102. 
2003

2010

«Bartolomé Herrera y la renovación del Perú». En Persona y Cultura Revista de la Universidad Católica San Pablo, año 2, N. 2, 88-99.

«Bartolomé Herrera, sacerdote». En Fernán Altuve-Febres Lores (comp.). Bartolomé Herrera y su tiempo (Actas del congreso conmemorativo del bicentenario del natalicio de Bartolomé Herrera 1808-2008). Lima: Sociedad Peruana de Historia, Editorial Quinto Reino.

Cateriano, Mariano Ambrosio

1908

Memoria de los Ilustrísimos Señores Obispos de Arequipa desde la erección de esta Iglesia hasta nuestros dias. Arequipa: Tipografía Quiroz.

Cubas, Ricardo 2001

«Una visión católica de la historia del Perú. El pensamiento y la labor peruanista de Bartolomé Herrera». En Raíces católicas del Perú. Lima: Vida y Espiritualidad.

De Asís, Agustín 1954 Bartolomé Herrera, pensador politico EEHA. Sevilla: Editorial CSIC - CSIC Press.

De la Puente, José Agustín 1965

Bartolomé Herrera. Lima: Editorial Universitaria. 
JOSÉ ANTONIO BENITO RODRÍGUEZ

De La Riva, José

1979

1935

FRANCISCO

2013

García y SAnZ, Pedro 1879

1964
Obras Completas X. Lima: PUCP.

Discursos académicos. Academia peruana, correspondiente de la Española de la Lengua. Lima: Impr. Torres Aguirre.

Lumen fidei. Disponible en el portal del Vaticano <http://www.vatican.va/holy_father/ francesco/encyclicals/documents/papafrancesco_20130629_enciclica-lumen-fidei_ sp.html>. Consulta hecha en 27/01/2014.

«Biografía del Ilmo. Sr. Dr. D. Bartolomé Herrera, vigésimo obispo de Arequipa». En Revista Católica III, pp.294-295.

Gran Unidad Escolar Bartolomé Herrera

Bartolomé Herrera. Homenaje en su centenario. 1864-1964. Lima: Escuela Nacional de Artes Gráficas, pp. 20-31.

Herrera, Bartolomé y Jorge G. Leguía

1930 Escritos y Discursos. Tomo II. Lima: Librería Francesca Científica y Casa Editorial. 
Herrera, Gonzalo y Rodrigo Herrera

1930

Bartolomé Herrera. Escritos y Discursos. Tomo I. Lima: Biblioteca de la República.

IWASAKI, Fernando

1984-1985

JiMÉNEZ BORJA, José

1949

JuAn Pablo II

1992

Mariátegui, José Carlos 1994

Martínez, Santiago

1933
Mariátegui Total: 100 años. Editado por Sandro Mariátegui Chiappe. Vol. 2. Lima: Empresa Editora Amauta, p. 2950.

«El Pensamiento Político de Bartolomé Herrera». Boletín del Instituto Riva Agüero, N. 13, p.138.

«Los Fines de la Educación en el Perú y don Bartolomé Herrera». En Revista Nueva Educación de la Universidad Nacional Mayor de San Marcos, N. 23, año IV.

Pastores dabo vobis. Disponible en <http:// www.vatican.va/holy_father/john_paul_ii/ apost_exhortations/documents/hf_jp-ii_ exh_25031992_pastores-dabo-vobis_sp.html>. Consulta hecha en 24/01/2014. 
JOSÉ ANTONIO BENITO RODRÍGUEZ

Moreno, Alfredo

1956

Repertorio de noticias breves sobre personajes peruanos Madrid: Sucs. de J. Sánchez Ocaña y Cía.

Putnam, Jorge 2001

«Fundamento teológicos de la actuación pública de Bartolomé Herrera (1808-1864)». En Anuario de la Historia de la Iglesia Pamplona, N. 10, pp.514-519.

2008

«Bartolomé Herrera (1808-1864). Bicentenario de su nacimiento. Un intento de reforma moral y educativa y la defensa de los valores». Documento disponible en <http://www.capellania.udep.edu. pe/boletin/capinf302.html>. Consulta hecha en 01/11/2010.

Valle, Manuel Teodoro del

1864

Oración fúnebre que en las exequias mandadas celebrar por la Cámara de Diputados el 17 de setiembre de 1864, por el descanso eterno del Ilmo. Sr. Dr. Bartolomé Herrera. Lima: Imprenta de El Mercurio, CVU 254 S/4 4.

VARGAS UGARTE, Rubén

1970
El Real Convictorio Carolino y sus dos luminares. Lima: Editorial Milla Batres. 
BARTOLOMÉ HERRERA, EL SACERDOTE EDUCADOR

1984

Historia General del Perú. 2a ed. Tomo Ix. La República (1844-1879). Lima: Editorial Milla Batres. 